6 - ORIGINAL ARTICLE

EXPERIMENTAL ONCOLOGY

\title{
Ponderal behavior of rats fed an omegas 3, 6 and 9 enriched diet submitted to colon carcinogenesis induced by azoxymethane ${ }^{1}$
}

\author{
Idália Maria Brasil Burlamaqui', Conceição Aparecida Dornelas ${ }^{\mathrm{II}}$, Lara Albuquerque de Brito ${ }^{\mathrm{III}}$, José Wilson Meireles Trindade \\ Júnior ${ }^{\text {III }}$, Rafael Moura e Sucupira ${ }^{I I I}$, Lara Burlamaqui Veras ${ }^{\mathrm{IV}}$, Orleâncio Gomes Ripardo de Azevedo ${ }^{\mathrm{V}}$, Paulo Roberto Leitão \\ Vasconcelos $^{\mathrm{VI}}$, Lusmar Veras Rodrigues ${ }^{\mathrm{VII}}$ \\ IFellow PhD degree, Postgraduate Program in Surgery, Department of Surgery, Federal University of Ceara (UFC), Fortaleza-CE, Brazil. Conception \\ and design of the study, acquisition of data, technical procedures, manuscript preparation.

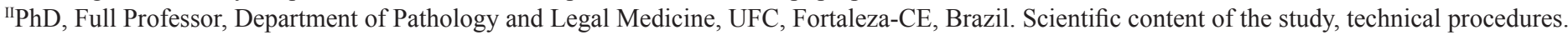

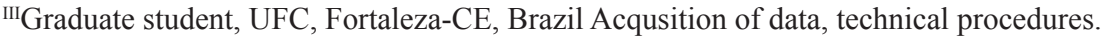

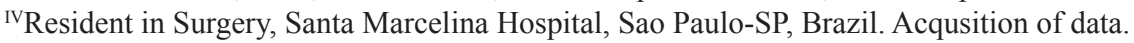 \\ ${ }^{v}$ Post Doctoral, Laboratory of Nutrigenomics, Department of Surgery, UFC, Fortaleza-CE. Statistical analysis. \\ ${ }^{\mathrm{VI} C}$ Coordinator, Postgraduate Program in Surgery, Department of Surgery, UFC, Fortaleza-CE, Brazil. Intellectual and scientific content of the study, \\ manuscript writing. \\ ${ }^{\mathrm{VII}} \mathrm{PhD}$, Associate Professor, Department of Surgery, UFC, Fortaleza-CE, Brazil. Conception and design of the study, manuscript writing, critical \\ revision.
}

\begin{abstract}
PURPOSE: To assess weight changes in rats fed diets with different ratios of omegas 3,6 and 9 submitted to colonic carcinogenesis induced by Azoxymethane (AOM).

METHODS: Sixty rats with three weeks of life were distributed into five groups of specific diets containing 12 animals each: GIStandard diet without adminstration of AOM, GII- Standard diet with adminstration of AOM; GIII- Hyperlipidic diet with adminstration of AOM; GIV-Normolipidic diet with adminstration of AOM; GV- Hypolipidic diet with adminstration of AOM. The weight and food intake of each group were assessed four times in each week throughout the experiment until euthanasia at 36th week.

RESULTS: GI and GII had no significant difference in weight. GI showed a significant increase when compared to GIII, GIV and GV. GII also showed a significant increase when compared to GIII, GIV and GV. When comparing intake of GI as compared to GII no significant difference was found, however such groups had higher intake than groups III, IV and V. There were found no difference in weight when comparing amoung rats with and without cancer within each groups: GII, GIII, GIV and GV.
\end{abstract}

CONCLUSIONS: Diets rich in omega 3, 6 and 9 reduced food intake and weight. Rats with colorectal cancer had no decrease in weight as compared to those without this condition in the same group.

Key words: Colorectal Neoplasms. Azoxymethane. Diet. Diet, High-Fat. Rats. 


\section{Introduction}

In recent decades, the ocidental alimentary habits have changed drastically as a result of changes in the lifestyle of the population. According to recent data from Brazilian Ministry of Health, the alimentary pattern in world has changed with industrialization and technological advances with subsequent change in family structure ${ }^{1}$. Thus, the incidence of obesity and another morbidities has increased, especially in development countries, a fact that leads to be considered a global epidemic ${ }^{2}$.

According to the World Health Organization (WHO), the occurrence of obesity in individuals reflects the interaction between environmental and dietary factors associated with genetic background. Among dietary factors, the most important is the excessive intake of lipids, increasing the adipose tissue ${ }^{3}$. This adipose tissue, which in the past was considered a passive storage tissue fat, has been shown the role in producing and releasing a large amount of hormones, growth factors, cytokines, adipokines and inflammatory signaling molecules, which may affect cell behavior in all phases of growth ${ }^{4}$.

Changes in metabolism and body weight caused by fatty diets depend not only on the quantity but also the specific fatty acid composition ${ }^{5}$. Diets rich in saturated or trans fats may promote the onset of several chronic diseases such as diabetes, dyslipidemia, cancer and autoimmune diseases ${ }^{6}$. However, unsaturated fats diets rich in omega 3, 6 and 9 reduce the activity of liver enzymes related to fatty acid synthesis by reducing cholesterol and triglycerides leading to anti-inflammatory action and inhibiting proliferation and immune regulation of the cellular activity ${ }^{7,8}$.

The family of fatty acids is divided into polyunsaturated (PUFA), consisting of the omega-3 and 6, and monounsaturated (MUFA), omega-9. The omega-6 (linoleic acid and arachidonic acid) are found in vegetable oils such as coin and soybeans, and the omega-3 (alpha-linolenic acid, eicosapentaenoic acid (EPA) and docosahexaenóico (DHA), mainly in oils from cold-water and deep fish as salmon, herring, tuna and sardines, and vegetables such as flaxseed and soybeans. The omega-9 (oleic acid) is present in high concentration, mainly olive oil, but also grape seed oil, rapeseed oil, sesame oil, sunflower oil, soybean oil, palm oil and marine animals such as the shark and cod fish ${ }^{9}$.

Animals fed with linoleic acid-rich oil had higher number of lymphocytes in intestinal mucosa, probably due to the inflammatory response of arachidonic acid metabolism resulting from linoleic acid. It is known that the modulating role of the inflammatory response depends on the ratio of w- 6 / w-3 in diet. Furthermore some studies showed that fish oil, flaxseed oil and olive oil promote different effects on the lipid profile, in the preservation of the intestinal villi and lymphocyte migration in mucosa of wistar rats, probably due to the difference in composition these fatty acids ${ }^{10}$.

According to some studies, weight gain is proportional to the amount of dietary fat, and a fatty diet provides greater weight gain. However, it is evident that a high fat diet rich in omega-3 has a protective effect on the accumulation of retroperitoneal and epididymal fat, improve in insulin resistance, but does not interfere with total body weight ${ }^{11,12}$.

Although several studies in some types of cancer, including colorectal, do not elucidate whether the increased risk of cancer in obese people is due to excess weight, more studies are necessary to indicate whether a diet rich in fat, the increased calories and the lack of physical activity, or a combination of these factors, play a more significant role.

The aim is to evaluate changes in weight of rats Wistar fed with hyperlipidic, normolipidic and hypolipidic diet rich in omega 3, 6 and 9, submitted to AOM-induced colon carcinogenesis.

\section{Methods}

The study was conducted after evaluation of the Ethics Committee on Animal Research of the Federal University of Ceara (CEPA/UFC) under the protocol number 09 of the day 03/02/2009 and according to the International Standards for Biomedical Research on Animals.

A total number of 60 rats (Rattus norvegicus albinus, Mammalia Rodentia, Muridae) of Wistar strain, male, were obtained from the Central Animal Vivarium of the Federal University of Ceara, with three weeks of age and weighing between $30 \mathrm{~g}$ and $40 \mathrm{~g}$. All animals were treated with antihelmintic for veterinary use, $1 \mathrm{ml} / \mathrm{kg}$ body weight $\left(\right.$ Basken $^{\circledR}$ - and pamoate Pyrantel pamoate oxantel) and separated individually in polypropylene cages, under appropriate conditions of humidity, temperature and lighting Laboratory of Experimental Surgery, Department of Surgery, Faculty of Medicine, Federal University of Ceara. In addition the rats received water and food ad libitum.

\section{Experimental design}

The animals were identified, weighed and randomly assigned to the cages, forming five groups of specific diets, containing 12 animals each. Euthanasia was performed at the 36th week of the experiment. 
Group I- (GI): Control group with rats receiving a standard diet (SD) and not exposed to AOM - The standard diet was Bio-tec Biobase Rats and Mice ${ }^{\circledR}$ with a total of $4444 \mathrm{kcal} /$ $\mathrm{kg}$ and distribution the following caloric: 59\% carbohydrate, $29 \%$

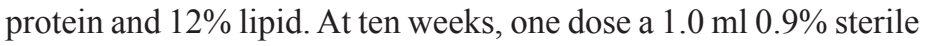
saline solution (SS), intraperitoneal (IP), was administered once a week for two weeks. (Figure 1)

Group II - (GII): Control group with rats receiving a standard diet (SD) and exposed to AOM - The standard diet was Bio-tec Biobase Rats and Mice ${ }^{\circledR}$ with a total of $4444 \mathrm{kcal} / \mathrm{kg}$ and distribution the following caloric: $59 \%$ carbohydrate, $29 \%$ protein and $12 \%$ lipid. At ten weeks, one dose a $20 \mathrm{mg} / \mathrm{kg}$ AOM, IP, was administered once a week for two weeks. (Figure 1)

Group III - (GIII): Study group with rats receiving a hyperlipidic diet (DH) and exposed to AOM - The hyperlipidic diet was rich in unsaturated fatty acids (omega 3,6 and 9) and composed of $11.8 \mathrm{~g}$ of dextrin Nutri $+9.5 \mathrm{~g}$ Oil (1.14g Oil Flaxseed $+4.18 \mathrm{~g}$ Canola Oil $+2.75 \mathrm{~g}$ Olive Oil $+1.42 \mathrm{~g}$ of Medium Chain Triglycerides $(\mathrm{MCT})+16.5 \mathrm{~g}$ Protein Nutri HWP, totaling 4570 $\mathrm{kcal} / \mathrm{kg}$ and distribution the following caloric: $25 \%$ carbohydrate, $30 \%$ protein and $45 \%$ lipid. At ten weeks, one dose a $20 \mathrm{mg} / \mathrm{kg}$ AOM, IP, was administered once a week for two weeks. (Figure 1)

Group IV - (GIV): Study group with rats receiving a normolipidic diet (DH) and exposed to AOM - The normolipidic diet was rich in unsaturated fatty acids (omega 3, 6 and 9) and composed of $18 \mathrm{~g}$ Nutri dextrin $+6,2$ Oil g (0.744 g Oil Flaxseed $+2,728$ g Canola Oil + 1,798 g Olive Oil +0.93 g TCM) +16.5 g Protein Nutri HWP, totaling $4170 \mathrm{kcal} / \mathrm{kg}$ and distribution the following caloric: $40 \%$ carbohydrate, $30 \%$ protein and $30 \%$ lipídio. At ten weeks, one dose a $20 \mathrm{mg} / \mathrm{kg}$ AOM, IP, was administered once a week for two weeks. (Figure 1)

Group V - (GV): Study group with rats receiving a hypolipidic diet (DH) and exposed to AOM - The hypolipidic diet was rich in unsaturated fatty acids (omega 3,6 and 9) and composed of $27 \mathrm{~g}$ of Nutri dextrin +2.5 Oil g $(0.3 \mathrm{~g}$ Linseed Oil $+1.1 \mathrm{~g}$ of Canola Oil $+1.725 \mathrm{~g}$ Olive Oil $+0.375 \mathrm{~g}$ TCM $)+16.5$ g Protein Nutri HWP, totaling $3761 \mathrm{kcal} / \mathrm{kg}$ and distribution the following caloric: $58 \%$ carbohydrate, $30 \%$ protein and $12 \%$ lipid. At ten weeks, one dose a $20 \mathrm{mg} / \mathrm{kg}$ AOM, IP, was administered once a week for two weeks. (Figure 1)

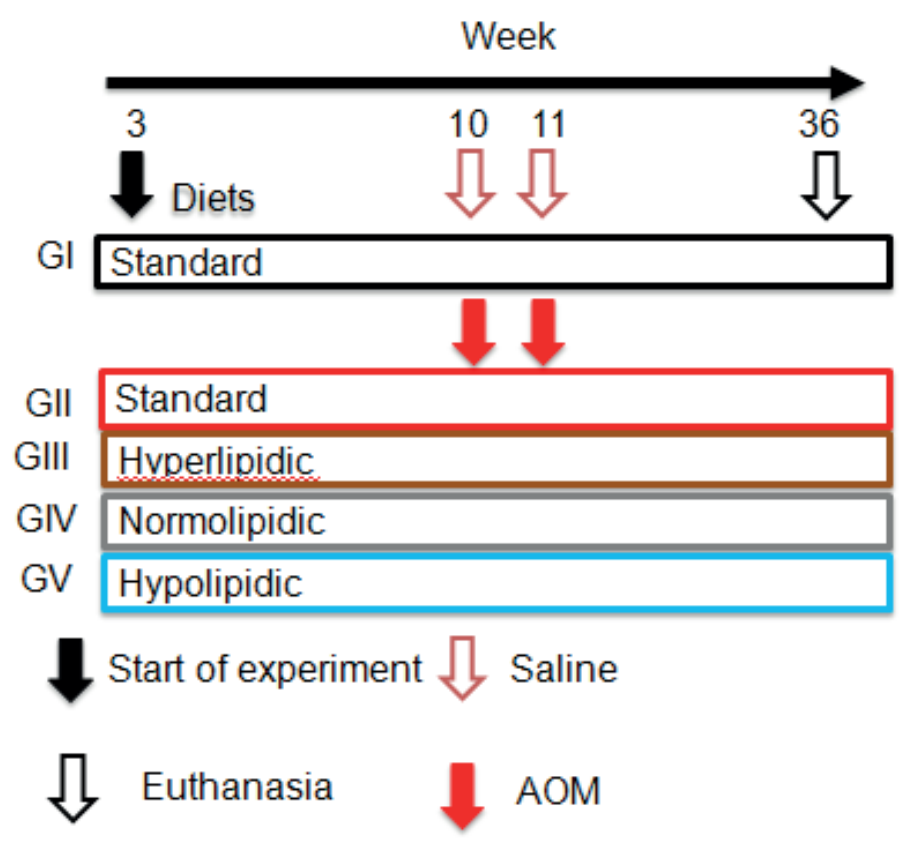

FIGURE 1 - Experimental design showing the groups and the respective periods during the study.

\section{Carcinogenesis inducer}

Azoxymethane (SIGMA-ALDRICH) was acquired at the presentation of $100 \mathrm{mg}$ and was diluted in sterile water for injection, to obtain a dose of $20 \mathrm{mg} / \mathrm{kg}$ of body weight, administered by IP injections in two consecutive doses, at weekly intervals.

\section{Clinical evalutaion}

The animals were clinicaly evaluated, by two investigators, daily throughout the experiment. Changes were observed in weight, behavior (reactivity, immobility), involuntary contractions, breathing, diarrhea, anorexia, piloerection, loss of body hair and ulcerations. The weighing of the animals was carried out 4 times a week until the day of euthanasia.

\section{Diets}

The animals were fed with the standard, hyperlipidic, normolipidic and hypolipidic diet and water ad libitum (Tables 1 and 2). 
TABLE 1 - Nutrients composition.

\begin{tabular}{|c|c|c|c|c|c|}
\hline Nutrient & Quantity (g) & Calories & Carbohydrates (g) & Proteins (g) & Lipids (g) \\
\hline \multicolumn{6}{|l|}{ Standard Diet } \\
\hline Biobase Bio-tec & 27 & 120 & 17.6 & 8.8 & 1.6 \\
\hline Total & 27 & 120 & 17.6 & 8.8 & 1.6 \\
\hline Total of calories $(\%)$ & & & $70.4(58.7 \%)$ & $35.2(29.3 \%)$ & $14.4(12.0 \%)$ \\
\hline \multicolumn{6}{|l|}{ Hyperlipidic Diet } \\
\hline Nutri dextrin & 11.8 & 44.84 & 11.21 & 0 & 0 \\
\hline Oils (mix) & 9.5 & 78.92 & 0 & 0 & 8.77 \\
\hline Nutri Protein HWP & 16.5 & 52.8 & 0 & 13.2 & 0 \\
\hline Total & 37.8 & 176.57 & 11.21 & 13.2 & 8.77 \\
\hline Total of calories $(\%)$ & & & $44.84(25.4 \%)$ & $52.8(29.9 \%)$ & $78.9(44.7 \%)$ \\
\hline \multicolumn{6}{|l|}{ Normolipidic Diet } \\
\hline Nutri dextrin & 18 & 68.4 & 17.1 & 0 & 0 \\
\hline Oils (mix) & 6.2 & 51.51 & 0 & 0 & 5.7 \\
\hline Nutri Protein HWP & 16 & 51.2 & 0 & 12.8 & 0 \\
\hline Total & & 171.11 & 17.1 & 12.8 & 5.7 \\
\hline Total of calories $(\%)$ & & & $68.4(40.0 \%)$ & $51.2(29.9 \%)$ & $51.5(30.1 \%)$ \\
\hline \multicolumn{6}{|l|}{ Hypolipidic Diet } \\
\hline Nutri dextrin & 27 & 102.6 & 25.65 & 0 & 0 \\
\hline Oils (mix) & 2.5 & 20.77 & 0 & 0 & 2.31 \\
\hline Nutri Protein HWP & 16.5 & 52.8 & 0 & 13.2 & 0 \\
\hline Total & & 176.17 & 25.65 & 13.2 & 2.31 \\
\hline Total of calories (\%) & & & $102.6(58.2 \%)$ & $52.8(30 \%)$ & $20.8(11.8 \%)$ \\
\hline
\end{tabular}

TABLE 2 - Lipid profile of the diets and ratio for omegas 3, 6 e 9.

\begin{tabular}{|c|c|c|c|c|}
\hline Lipid profile & Standard & Hyperlipidic & Normolipidic & Hypolipidic \\
\hline \multicolumn{5}{|l|}{ Fat } \\
\hline Poliinsaturada & $54 \%$ & $26.50 \%$ & $26.50 \%$ & $26.50 \%$ \\
\hline Monoiinsaturada & $24 \%$ & $50.20 \%$ & $50.20 \%$ & $50.20 \%$ \\
\hline Saturada & $15 \%$ & $23.30 \%$ & $23.30 \%$ & $23.30 \%$ \\
\hline \multicolumn{5}{|l|}{ Ratio w 3, 6 e 9} \\
\hline w6:w3 & $8: 1$ & $1,4: 1$ & $1,4: 1$ & $1,4: 1$ \\
\hline w9:w6 & $0.4: 1$ & $3.2: 1$ & $3.2: 1$ & $3.2: 1$ \\
\hline Poli:Sat & $5.2: 1$ & $3.3: 1$ & $3.3: 1$ & $3.3: 1$ \\
\hline
\end{tabular}




\section{Surgery procedings and euthanasia}

Twenty six weeks after the first AOM injection the animals were anesthetized with $80 \mathrm{mg} / \mathrm{kg}$ ketamine and $8 \mathrm{mg} / \mathrm{kg}$ xylazine by IP injections. They were positioned supine for surgery outset, undergoing laparotomy by midline xypho-pubic incision followed by protocolectomia. This was followed by measuring, weighing and evaluating for the presence of colon tumors. The intestinal segment was opened and washed with saline and immersed in a solution of $10 \%$ formalin for fixation. Then the animals were sacrificed by section of the abdominal aorta.

\section{Statistical analysis}

For statistical analysis the softwares GraphPadPrism 5.0 (California, USA) and Excel (New York, USA) were used. The normality test of Kolmogorov-Smirnov was also applied. Quantitative variables were presented in graphs with parametric trendlines or column charts showing mean and standard deviation (mean $\pm \mathrm{SD}$ ) and compared by $t$ test Student, with a significance level of $5 \%(p<0.05)$.

\section{Results}

Weight changes

\section{Body Weight}

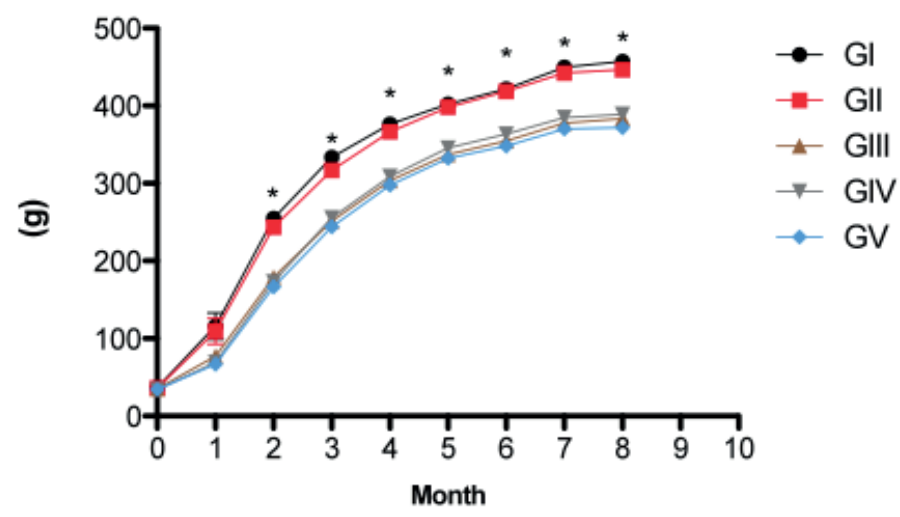

* p<0,05 GI and GII vs GIII, GIV and GV

FIGURE 2 - Mean of weight gain in each group in each month.

The begining (month 0), there was no statistically significant difference in weight among the five groups (Student $\mathrm{t}$ test / $\mathrm{p}>0.05)$. By the 1 st month of the experiment, it was observed that the weight of the animals in groups III, IV and V was significantly lower when compared to the weights of the animals of group I and II (Student $\mathrm{t}$ test $/ \mathrm{p}<0.05$.) The $p$ values obtained in the last month: GIII $(p=0.0045), \operatorname{GIV}(p=0.0110)$ and GV $(p=$
$0.0018)$ compared to GI, and GIII $(p=0.0034)$, GIV $(p=0.0149)$ and GV $(\mathrm{p}=0.0013)$ compared with GII.

\section{Distribution of intake}

Food intake

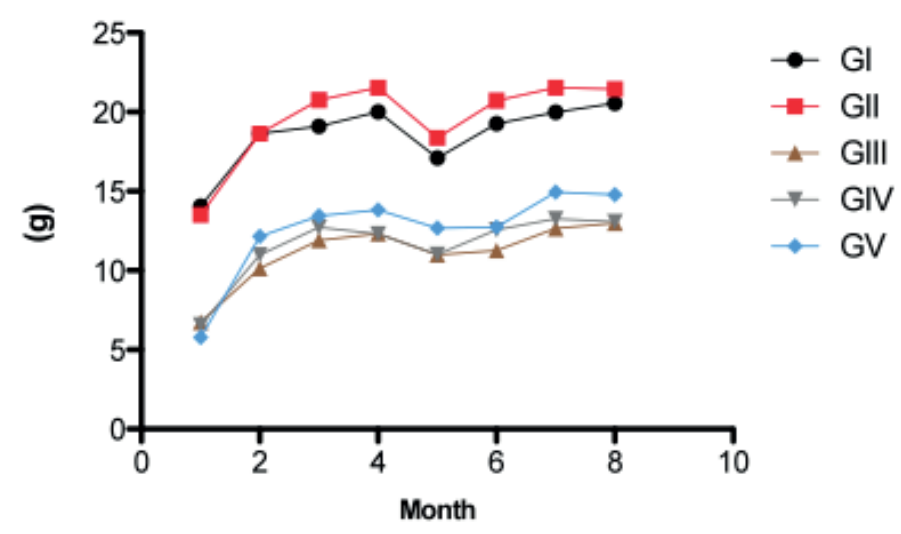

FIGURE 3 - Mean of intake in each group during the experiment.

When comparing the intake of group I with group II there was no statistically significant difference $(p=0.997)$, but between group I and groups III, IV and V was significant difference with $\mathrm{p}$ $<0.001, \mathrm{p}<0.001$ and $\mathrm{p}=0.004$, respectively. In the comparison of intakes of group II with group III, IV and V, there was also a significant difference with $\mathrm{p}<0.001, \mathrm{p}<0.001$ and $\mathrm{p}=0.002$, respectively.

Distribution of body weight of the rats with / without cancer groups at the end of the experiment

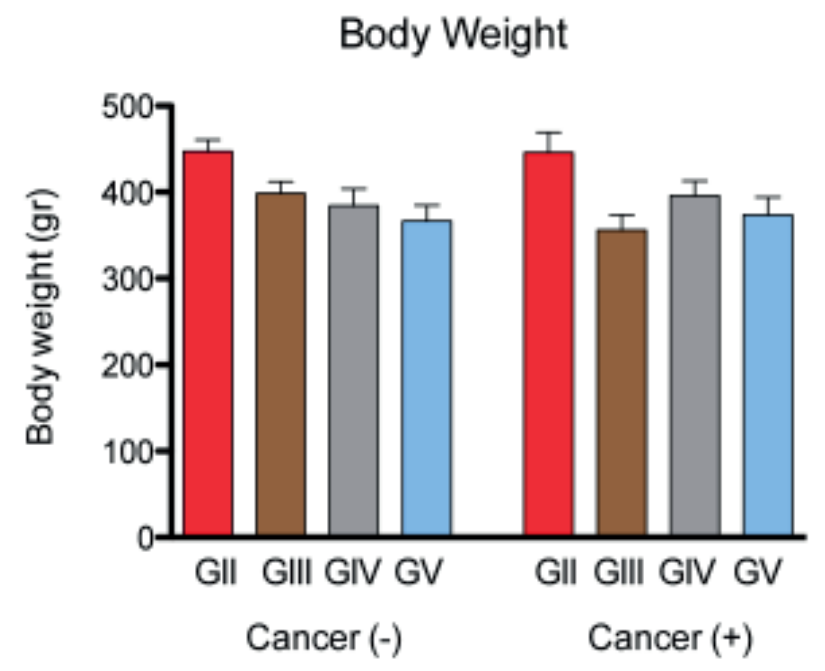

FIGURE 4 - Mean \pm SD of the animals with and without cancer in each group in the end of experiment. 
There was no difference in weight mean compared between rats with cancer and without cancer: GII $(\mathrm{p}=0.9514)$, GIII $(p=0.0965)$, GIV $(p=0.7018)$ and GV $(p=0.8220)$.

\section{Discussion}

The cancer patients, as well as anorexia, exhibit metabolic abnormalities that impair anabolism causing severe weight loss leading to cachexia. The factor tumor to mobilization of lipids stimulates lipolysis, providing the loss of adipose tissue. The decrease in skeletal muscle mass is a result of decreased protein synthesis and increased protein degradation by activating the NF$\mathrm{kB}$ pathway ${ }^{13}$. EPA acts by inhibiting protein degradation pathway and has a modulating effect on pro-inflammatory cytokines, the hepatic acute phase proteins, eicosanoids and tumor factors promoting a beneficial effect on body composition by modulating the loss of lean mass ${ }^{14}$.

Since the beginning of the experiment until euthanasia, it was observed that the weight of the animals in groups III, IV and $\mathrm{V}$ was significantly lower when compared to the weights of the animals of group I and II. The group I and II were fed with the same standard diet and no present significant difference in weight at the administration of AOM ( $\mathrm{p}=1.000), 20 \mathrm{mg} / \mathrm{kg}$ weight, and at the end of the experiment $(p=1.000)$. Therefore AOM did not affect the food intake of the animals as well as the final body weight. Possible explanation for this finding of low weight in the diets studied groups is that the amount of intake was greater in group I and II than in groups III, IV and V (Figures 2 and 3).

A recent study demonstrated that a saturated fat diet injured the hypothalamus and caused local inflammation, neuronal death and consequent loss of the ability of perception of timing the signal to burn or storage food. The intake of omega-3, for its anti-inflammatory action, restored neural control hunger and increased energy expenditure, promoting weight loss. It was also demonstrated that animals fed diets with lower concentrations of omega-3 and 9 presented even higher reduction in hypothalamic inflammation, restoring metabolic derangements regarding food and termogenics ${ }^{15}$. These findings were similar to those found in the group fed hypolipidemic diet in this research, which in absolute values received lower amounts of omega- 3 and 9 although the relationship between the omegas (w6: w3 and w9: w6) remained constant.

PUFA supplementation helps to reduce body fat by stimulating fat oxidation mainly in healthy adults. EPA and DHA increases weight loss and regulate gene expression from adipose tissue in a manner similar to caloric restriction regardless of loss of fat mass ${ }^{16}$.

The beneficial effects of the PUFA are well-known in adipose tissue such as preventing hyperplasia and hypertrophy of adipose tissue, induction of mitochondrial biogenesis in adipocytes, inducing the secretion of adiponectin and reduction of adipose tissue inflammation. The action of adiponectin is more pronounced in the epididymal fat in the abdomen than in subcutaneous fat, contributing to increase the sensitivity of insulin ${ }^{17}$.

Omega-3 alter indicators related to the development of the metabolic syndrome and present beneficial effects on lipid profile and glucose, preventing excess weight gain. The mechanism by which the flaxseed oil acts in reverse of abdominal obesity remains unknown. Evidence suggests that polyunsaturated fatty acids in the diet may act as modulators for the deposition of body fat ${ }^{18}$.

Another aspect is that the animals in groups of diets enriched with omegas presents diarrhea since the start of the experimentation contributing to the low body weight. It is known that high doses of omega-3 have few collateral effects, diarrhea recognized as the main one ${ }^{13}$.

There were significant differences in food consumption which was lower in the study group as compared to controls. This can be explained by the composition of the diets, which are rich in soluble fiber. These fibers have a great ability to form gel. This leads to a decrease in the rate of gastric emptying, and prolongation of satiety, resulting in reduced food intake ${ }^{18}$.

The rats with CRC showed no decrease in weight in comparison with those without this condition independently of the offered diet (Figure 4). This finding is consistent with the literature, for colorectal cancer in early stage as it is asymptomatic and does not compromise the overall condition of affected individuals ${ }^{19}$.

Anthropometric data obtained from a recent study indicated the prevalence of normal weight $(45.71 \%)$, overweight (35.71\%), obesity (12.86\%) and thinness $(5.71 \%)$ in patients with colorretal cancer $^{20}$. These findings are similar to the literature, because malnutrition is not common in this condition, which can not be explained by the no impaired food intake, malabsorptive disorders and obstructive factors.

\section{Conclusions}

Diets rich in omegas (3,6 and 9) reduce food intake and weight mass in rats submitted to AMO carcinogenesis. Rats with colorectal cancer had no weight reduction as compared to animals without this disorder inrespective of the diet used. 


\section{References}

1. Instituto Nacional do Câncer (INCA). Disponível em: http://www. inca.gov.br/conteudo_view.asp?ID=18.

2. Pereira LO, de Francischi RP, Lancha Jr AH. Obesity: dietary Intake, sedentarism and insulin resistance. Arq Bras Endocrinol Metabol. 2003;47(2):111-27.

3. Feoli AM, Roehrig C, Rotta LN, Kruger AH, Souza KB, Kessler AM, Renz SV, Brusque AM, Souza DO, Perry MLS. Serum and liver lipids in rats and chicks fed with diets containing different oils. Nutrition. 2003;19:789-93.

4. Ballard-Barbash R. The emerging evidence about the role of obesity in cancer. NCI Cancer B. 2011;8(22).

5. Campos FG, Waitzberg DL, LogulloWaitzberg AF, Habr-Gama A, Kiss DR, Gama-Rodrigues J. Diet and colorectal cancer: current evidence for etiology and prevention. Nutr Hosp. 2005;20(1):18-25.

6. Simopoulos AP. Evolutionary aspects of diet, the omega-6/omega-3 ratio and genetic variation: nutritional implications for chronic diseases. Biomed Pharmacother. 2006;60(9):502-7.

7. Steemburgo T, Dall'alba V, Gross JL, Azevedo MJ. Fatores dietéticos e síndrome metabólica. Arq Bras Endocrinol Metab. 2007;51(9):1425-33.

8. Burlamaqui IMB, Dornelas CA, Valença Jr JT, Mota DMC, Mesquita FJC, Veras LB, Vasconcelos PRL, Rodrigues LV. Effect of a hyperlipidic diet rich in omegas 3, 6 and 9 on aberrant crypt formation in rat colonic mucosa. Acta Cir Bras. 2012;27(1):30-6.

9. Rique ABR, Soares EA, Meirelles CM. Nutrição e exercício na prevenção e controle das doenças cardiovasculares. Rev Bras Med Esporte. 2002;8(6):244-54.

10. Brant LHC, Cardozo LFMF, Velarde LGC, Boaventura, GT. Impact of flaxseed intake upon metabolic syndrome indicators in female Wistar rats. Acta Cir Bras. 2012;27(8):537-43.

11. Pellizzon M, Buison A, Ordiz F Jr, Santa Ana L, Jen KL. Effects of dietary fatty acids and exercise on body-weight regulation and metabolism in rats. Obes Res. 2002;10(9):947-55.

12. Belzung F, Raclot T, Groscolas R. Fish oil n-3 fatty acids selectively limit the hypertrophy of abdominal fat depots in growing rats fed high-fat diets. Am J Physiol. 1993;264(6):1111-8.

13. Carmo MCNS, Correia MITD. The role of omega-3 fatty acids in cancer. Rev Bras Cancerol. 2009;55(3):279-87.

14. Boddaert AS, Gerritsen WR, Pinedo HM. On our way to targeted therapy for cachexia in cancer? Curr Opin Oncol. 2006;18:335-40.

15. Cintra DE, Ropelle ER, Moraes JC, Pauli JR, Morari J, Souza CT, Grimaldi R, Stahl M, Carvalheira JB, Saad MJ, Velloso LA. Unsaturated fatty acids revert diet-induced hypothalamic inflammation in obesity. PLoS One. 2012;7(1):e30571.

16. Simopoulos AP. Genetic variants in the metabolism of omega- 6 and omega-3 fatty acids: their role in the determination of nutritional requirements and chronic disease. Exp Biol Med. 2010;235:785-95.

17. Kopecky J, Rossmeisl M, Flachs P, Kuda O, Brauner P, Jilkova Z, Stankova B, Tvrzicka E, Bryhn M. N-3 PUFA: bioavailability and modulation of adipose tissue function. Proc Nutr Soc. 2009;68(4):361-9.

18. Rosa DD, Sales RL, Moraes LFS, Lourenço FC, Neves CA, Sabarense CM, Ribeiro SMRo, Peluzio MCG. Flaxseed, olive and fish oil influence plasmatic lipids, lymphocyte migration and morphometry of the intestinal of Wistar rats. Acta Cir Bras. 2010;25(3):275-80.

19. Continente AJC, Pluvius CC, Martinez CV. Nutrición y neoplasias digestivas. Bras Nutr Clin. 2002;17:53-63.

20. Fortes RC, Recôva VL, Melo AL, Novaes MRCG. Hábitos dietéticos de pacientes com câncer colorretal em fase pós-operatória. Rev Bras Cancerol. 2007;53(3):277-89.

\section{Correspondence:}

Idália Maria Brasil Burlamaqui

Avenida Beira Mar, 3680/2001

60165-121 Fortaleza-CE Brasil

Tel: (55 85)3267-5780

idaliaburlamaqui87@hotmail.com

Received: June 12, 2013

Review: Aug 14, 2013

Accepted: Sept 12, 2013

Conflict of interest: none

Financial source: Postgraduate Program in Surgery and Experimental Surgery Laboratory (LABCEX), Federal University of Ceara

${ }^{1}$ Research performed at Laboratory of Experimental Surgery, Department of Surgery, Faculty of Medicine, Federal University of Ceara (UFC), Fortaleza-CE, Brazil. Part of PhD degree thesis, Postgraduate Program in Surgery. Tutor: Lusmar Veras Rodrigues. 